\title{
END-TO-END BRONCHIAL ANASTOMOSIS AFTER ACCIDENTAL DIVISION OF THE STEM BRONCHUS
}

\author{
BY \\ J. MATHEY AND G. OUSTRIERES* \\ Paris
}

(RECEIVED FOR PUBLICATION NOVEMBER 3, 1950)

In recent years reconstitution of bronchial continuity, after simple division or the removal of a circumferential section of the wall, has been the subject of experimental work. On the other hand, clinical observations of bronchial anastomosis in man are still rare. In the course of a difficult resection of the left lower lobe and lingula we accidentally divided the stem bronchus, and acquaintance with results obtained experimentally in animals enabled us to re-establish bronchial continuity and so to conserve the upper lobe.

\section{Case History}

A woman, aged 27, was referred to us by Dr. Pruvost on September 28, 1949, suffering from bronchiectasis of her left lower lobe and lingula.

In 1926, at the age of 3 , she had had measles and left pulmonary congestion. In 1931 there had been further trouble in the lung, with haemoptyses and the appearance in radiographs of a triangular shadow at the left base. From this time on, the patient had had numerous acute episodes with purulent sputum and haemoptysis.

In 1932 a left phrenicectomy was performed, but the acute episodes with purulent expectoration and haemoptyses, alternating with remissions, persisted up to 1948 . During the whole of the latter period she was treated by bronchial aspirations and both local and systemic penicillin, but while this therapy ameliorated the acute attacks it did not influence the general condition.

On examination the patient appeared to be in good general health, and apyrexial, but she continued to expectorate 40 to $50 \mathrm{ml}$. of muco-purulent sputum a day.

Radiographs and bronchograms showed bronchiectasis of the left lower lobe and of the lingular segment of the upper lobe. The diaphragm on the left side was high. The affected areas of the lung were much shrunken.

A pre-operative régime of bronchial aspirations and intrabronchial penicillin administered through a Métras catheter was instituted, and the sputum was reduced to about $10 \mathrm{ml}$. a day.

Operation was performed on December 9, 1949, and the anaesthetic (pentothal, cyclopropane, and curare) was given by Dr. Chateaureynaud.

The chest was entered through the sixth interspace, and the pleura found free. The lower lobe and lingula were atelectatic. The fissure was opened, and the pulmonary artery ligated and divided above its lingular branch. The inferior pulmonary vein was then tied. The dissection of the bronchus proved difficult on account of considerable retraction and of a mass of lymphatic glands adherent to the bronchial tree. After clamping and division of the bronchus it became evident that the section had been made through the stem bronchus, above its upper lobe branch.

\footnotetext{
* Translated by Geoffrey Flavell, F.R.C.S.
} 
The anaesthetist was asked to place the tracheal catheter in the right bronchus, thus ensuring regular ventilation without the surgeon having to clamp the left stem bronchus.

The lower lobe and lingula having been removed, it was decided to restore the bronchial continuity by an end-to-end anastomosis between the stem bronchus and the upper lobe bronchus beyond the lingular branch. This was carried out with everting sutures, of the continuous Blalock type on the posterior semi-circumference, and simple mattress stitches anteriorly.

The anaesthetist then replaced the catheter in the trachea ; the suture line was found to be air-tight, and the upper lobe was re-expanded normally. The whole suture line was then buried under the mediastinal pleura, a water-sealed pleural drain inserted, and the chest closed.

On the day following operation the left upper lobe was atelectatic. At bronchoscopy the anastomosis was found obstructed by a fragment of mucus the size of a pea. After aspiration the air-way was restored, and radiographs showed that the lobe had aerated. To maintain the air-way five bronchoscopies were necessary during the first 12 days.

Five weeks after operation the patient left hospital, in good condition both locally and generally, the upper lobe being perfectly aerated.

In July, 1950, more than six months after operation, the patient was seen again,

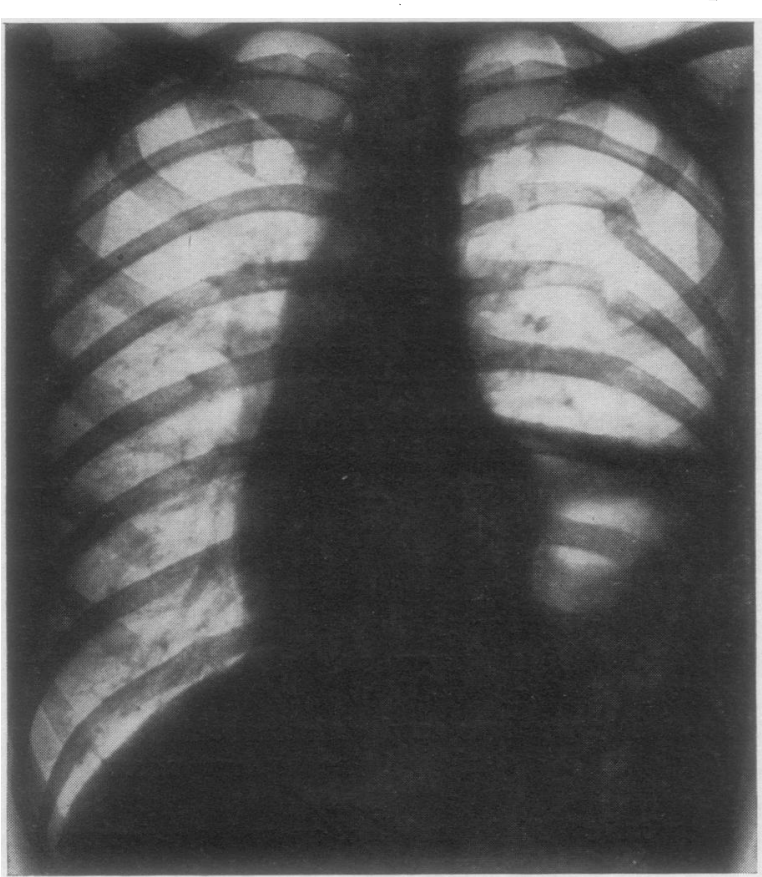

Fig. 1. and had no trouble to report. The upper lobe was perfectly aerated. A bronchoscopy showed that the trachea was normal; the carina was also normal, but it moved to the right on inspiration. The left stem bronchus was normal. At the site of the bronchial suture there was a right-angled bend, but the lumen of the upper lobe bronchus was widely patent.

Comparison of radiographs taken on forced inspiration and on forced expiration showed that before expiration there was mediastinal displacement to the opposite side. The interpretation of this phenomenon is somewhat difficult, but it was not due to obstruction in the left bronchial tree. We are inclined to blame emphysema of the left upper lobe or perhaps, more simply, the left diaphragmatic paralysis (Fig. 1).

\section{Discussion}

Reparatory surgery of the bronchi and trachea has so far involved two rather different problems: on the one hand repair of tissue loss in the wall, not affecting the continuity of the lumen; on the other hand, restoration of tracheal or bronchial continuity after complete circular division, or even ablation of a segment of the tube. Experimentally the problem of surgical repair of the trachea or bronchi was 
tackled with success by Taffel (1940). He was able to repair " defects created by the excision of full-thickness windows from the cervical trachea " with patches of fascia. The results were satisfactory.

Daniel (1948) successfully repeated Taffel's experiments and, further, used rigid tubes of glass, of stainless steel, and of vitallium to replace complete circular segments of the trachea or bronchus. In favourable cases the tube became encased by granulation tissue in which cartilage developed, thus forming a satisfactory anatomical restoration. But the continued presence of a voluminous foreign body in the lumen presented serious late complications.

Grindlay, Clagett, and Moersch (1949), after having used polythene tubes, expressed themselves thus: "Our main finding of interest in this series was that such tubes tended to become dislodged and expelled." They rejected prostheses in favour of direct suture (1950).

In 1949 Jackson, Lefkin, Tuttle, and Hampton presented their work on end-toend bronchial anastomosis after bronchial division, or resection of a previously induced stenosis. After having used two different techniques, simple end-to-end closure and everting cuff closure, they decided in favour of the latter.

The operations we have performed in anastomosing the stem bronchi of dogs and on the cervical trachea of rabbits have convinced us of the superiority of everting sutures, as much for immediate integrity as for final healing. In all cases we have paid particular attention to covering the suture line with peri-bronchial or peri-tracheal cellular tissue. The use of gelatin sponges, recommended by Hanlon (1948), has seemed to us superfluous when there is tissue available in the vicinity of the suture-line.

Jackson (1950) replaced stem-bronchial segments with tracheal cylindrical grafts taken from other dogs and used at once or preserved by refrigeration. The two bronchial segments were engaged in the larger tracheal cylinder, which thus served as a "muff."

Before becoming acquainted with Jackson's work, we had successfully worked with bronchial and tracheal grafts, but we used everting sutures. On the whole Jackson seems to us to provide the best solutions to the two essential problems: the use of an everting suture whenever the ends can easily be brought into contact, and of a homoplastic graft when the tissue loss is too great. The technique of how to fix the graft may be argued: a surrounding "muff" in the manner of Jackson, or simple everting suture as practised by ourselves. On the other hand, the use of prosthetic tubes, whatever their nature, seems to us to carry an undue risk of late complications.

In man repair operations on the trachea and bronchi are very much rarer. We have been able to gather from the literature a certain number of repairs of lateral tissue loss of the trachea and bronchi. Belsey (1946) was the first to reconstitute a trachea with fascia-wrapped spiral stainless steel wire. Recently (1950) he published two new cases of reconstruction of the trachea for malignant tumour of the trachea; one of them was particularly interesting because it concerned a recurrence in the trachea after right pneumonectomy for carcinoma. Gibbon (1948) used a costal cartilage and a pedicle of parietal pleura, Rob and Bateman (1949) tantalum gauze and fascia. Gebauer (1950a) proposed an original technique for bronchial reconstruction, using partly the experimental results of Taffel, Hanlon, and Daniel, and 
partly recent advances in the use of skin in plastic and reparative surgery. In four cases of bronchial stenosis this procedure allowed of a satisfactory reconstruction, with the aid of a dermal graft reinforced by steel wire. The long-term results, after more than a year, have confirmed the value of Gebauer's operation.

None the less, success in bronchial or tracheal repair after complete division, or the resection of a circular portion, is still exceptional. Clagett, Grindlay, and Moersch (1948) failed, using a prosthetic tube, to anastomose the trachea and left bronchus after segmental resection of the trachea for a tumour. Similarly Gebauer (1950b) failed in trying to deal with a tracheal stenosis by replacing the trachea with an artificial trachea made of steel wire and fascia lata. Griffith (1949) carried out an end-to-end anastomosis after resection of a traumatic stenosis. However, one must note that the division of the bronchus had been incomplete, leaving intact a part of the posterior wall and sparing the bronchial artery.

The only instance that we have been able to find of anastomosis following complete resection of a circular segment of bronchus is that of Tuttle (1949), which was carried out in an identical manner to our own. It concerned a difficult resection of the apical segment of the left lower lobe and lingula, in which, on account of retraction due to a previous operation, the stem bronchus was accidentally divided. Bronchial continuity was restored by end-to-end anastomosis, and recovery followed after a transitory atelectasis on the fourth day. The final result was good, the upper lobe being aerated, but no function tests were carried out.

In our case the anatomical result is good, the bronchus patent, and the upper lobe aerated, though it has not been possible to estimate precisely the function, since the patient has not been submitted to a separate bronchospirometry. It is possible that it is not perfect, as there is some mediastinal displacement on respiration. We think that the previous phrenicectomy plays an important part in this phenomenon, and that in man, as in the animal, bronchial anastomosis permits normal functioning of the lung beyond it.

\section{SUMMARY}

We report a successful case of end-to-end bronchial anastomosis in man.

Experimental work published up to the present shows that the problem of bronchial anastomosis and of the replacement of tissue loss by grafts is solved so far as experimental animals are concerned.

Observations of tracheo-bronchial surgical repair in man are still very few, but permit one to foresee that in a certain number of cases these conservative techniques will supplant mutilating measures of pulmonary extirpation.

Belsey, R. (1946). Thorax, 1, 39.

\section{REFERENCES}

- (1950). Brit. J. Surg., 38, 200.

Clagett, O. T., Grindlay, J. H., and Moersch, H. J. (1948). Arch. Surg., Chicago, 57, 253.

Daniel, R. A. (1948). J. thorac. Surg., 17, 335.

Gebauer, P. W. (1950a). Ibid., 19, 604.

- (1950b). Amer. Rev. Tuberc., 62, 176.

Gibbon, J. H. (1948). J. thorac. Surg., 17, 349.

Griffith, J. L. (1949). Thorax, 4, 105.

Grindlay, J. H., Clagett, O. T., and Moersch, H. J. (1949). Proc. Mayo Clin., 24, 555.

Hanlon, C. R. (1948). Surg. Gynec. Obstet., 86, 551.

Jackson, T. L. (1950). J. thorac. Surg., 19, 623.

Lefkin, P., Tuttle, W., and Hampton, F. (1949). Ibid., 18, 630.

Rob, C. G., and Bateman, G. H. (1949). Brit. J. Surg., 37, 202.

Taffel, M. (1940). Surgery, 8, 56.

Tuttle, W. (1949). J. thorac. Surg., 18, 641. 